\title{
Diabetic care provided at a Diabetes Clinic at the largest Tertiary Care Hospital in Southern Sri Lanka: an audit
}

\author{
Sandini Wijeweera ${ }^{1}$, Chaminda Hettige ${ }^{1}$, M.K.Ragunathan ${ }^{2}$ \\ ${ }^{1}$ Registrar in Medicine, ${ }^{2}$ Consultant Physician, Teaching Hospital, Karapitiya, Galle. \\ e-mail address of the corresponding author, Dr. Sandini Wijeweera: sandinijayasinghe@yahoo.com
}

\section{Introduction}

Diabetes mellitus is a chronic metabolic disorder of intermediary metabolism. Diabetic patients develop many complications due to uncontrolled hyperglycemia and associated cardio-metabolic risk. In Sri Lanka, National Guidelines for the management of diabetes mellitus were formulated by a panel of local experts and published in 2007 through a WHO funded program.Recommendations are given in this guideline on patient follow up for the frequencies for basic investigations, and on risk assessment strategies. At the clinic setup it is expected that these guidelines are followed in delivering patient care. In this audit, we are planning to assess, to which extent these are followed up and where the deviations occur. At the same time we are planning to identify shortcomings at our clinic setup, and to give our suggestions to relevant authorities through the results obtained.

\section{Audit Standard}

The standard of this audit was defined by the recommendations given in the national guidelines, "Clinical Practice Guidelines for the Management of Diabetes Mellitus 2007”.

\section{The recommendations are;}

Blood glucose levels

Fasting Plasma Glucose (FPG) and $2 \mathrm{hr}$ Postprandial Glucose (PPG) should be monitored during each monthly clinic visit.

If only one test requested, it should be PPG two hours after main meal of the day.

HbA1C need to be monitored 3 monthly until good control is achieved and 6 monthly once the control is established.

\section{Hypertension}

Defined as blood pressure above 130/80 $\mathrm{mmHg}$.

Blood pressure should be checked and recorded in each monthly clinic visits.

\section{Cardiovascular risk assessment}

A12 lead ECG annually and lipid profile twice a year.

\section{Nephropathy screening}

Urine albumin should be checked annually.

If urine albumin is positive, urinary tract infection should be excluded.

Repeat in another 2 occasions in 3 months time

If $2 / 3$ becomes positive, urine macro-albumin is confirmed.

If urine macroalbumin is negative, urine microalbumin / creatinine ratio (ACR) should be assessed.

ACR should be checked annually.

\section{Retinopathy screening}

Ophthalmoscopy should be done at the time of diagnosis and then annually.

\section{Foot care}

Examine with monofilament test and Doppler pulse study. Repeat annually.

\section{Neuropathy screening}

Examine with monofilament and tuning fork annually.

\section{Method}

\section{Target population}

Patients attending the special diabetes clinic on Saturday morning at Teaching Hospital, Karapitiya.

\section{Setting}

In the clinic setup at Teaching Hospital, Karapitiya, plasma glucose levels and blood pressure monitoring are done at regular follow up clinics. 
Risk assessment of all the patients is being done at fairly well equipped Diabetes Centre (DC). Patients are referred to DC by medical officers at the clinic level and the patients have to be in a waiting list for risk assessment.

\section{Data collection}

The audit was conducted from $21^{\text {st }}$ of March, 2009 to $16^{\text {th }}$ of May 2009. We recruited every $5^{\text {th }}$ patient serially, registered at MDR clinic on each Saturday until total number of 100 patients were collected. Data collection was performed using a questionnaire filled by an investigator at the clinic by direct questioning and by review of notes.

\section{Data analysis}

Collected data were analyzed by comparing with audit standards.

\section{Results}

Forty males and 60 females were included in the audit. There was one patient in 20-29 year age group, 5 in the 30-39 year age group, 27 in the 40-49 year age group and 67 in the 50-59 year age group. Their duration of follow up is shown in Table 1.

Table 1- Duration of follow up.

\begin{tabular}{|l|l|l|l|l|l|l|l|}
\hline $\begin{array}{l}\text { Duration of } \\
\text { follow up (years) }\end{array}$ & $<1$ & $1-2$ & $2-3$ & $3-4$ & $4-5$ & $5-6$ & $>6$ \\
\hline Number of patients & 3 & 12 & 15 & 21 & 12 & 18 & 19 \\
\hline
\end{tabular}

Forty two of the patients had co-existent hypertension while seventy-three had dyslipidaemia. When we compared the audit results with audit standards the following findings were apparent.

Blood glucose levels were checked monthly in $84 \%$ of patients (Not Requested - 0, Not Affordable -2\%, Not Interested $-14 \%$ ). However, only $4 \%$ of patients had $\mathrm{HbA}_{1 \mathrm{C}}$ checked. (NR - 90\%, NA - 4\%, NI - 2\%).

All the patients $(100 \%)$ have undergone monthly blood pressure measurements.

In cardiovascular risk assessment only $70 \%$ had ECG done annually (NR-20\%, NA-0, NI-10\%,) and a lesser number, $59 \%$, has done lipid profile twice a year. (NR-18\%, NA-15\%, NI-8\%)

Regarding nephropathy screening, UFR was checked annually in 76\% (NR-15\%, NA-0, NI-9\%) while urine for microalbumin was checked only in $53 \%$ (NR-22\%, NA-13\%, NI-12\%).

Seventy-eight percent of patients had undergone retinopathy screening.

Only 7\% had undergone neuropathy screening annually while $11 \%$ had undergone foot care screening.

In addition we checked the usage of available resources in Teaching Hospital Karapitiya. We noticed that $96 \%$ of the patients were referred to Diabetic Center at least once and $84 \%$ of patients were referred for dietary advice.

\section{Conclusions}

Of the patients who participated in the audit:

- $84 \%$ met audit standards in blood glucose monitoring.

- $100 \%$ met audit standards in blood pressure monitoring

- $59 \%$ met audit standards in lipid profile monitoring and $70 \%$ met audit standards in ECG annually under cardiovascular risk assessment.

- $76 \%$ met audit standards in checking UFR and $53 \%$ met audit standards in checking for microalbuminuria under nephropathy screening.

- $78 \%$ met audit standards in retinopathy screening.

- $11 \%$ met audit standards in foot care monitoring.

- $7 \%$ met audit standards in neuropathy screening.

\section{Recommendations}

1. When analyzing why the audit standards were not met in certain areas, the main reason we could see was unavailability of free laboratory facilities for some costly tests such as urine for microalbumin. Therefore we recommend making these tests available in hospital at least for patients with a low income. 
2. There is a long waiting list for an appointment in Diabetic Center, which leads to not meeting the audit criteria in some screening procedures as those are only being done there currently.(foot care, neuropathy screening) Therefore we recommend to allocate more number of patients per day to Diabetic Center to make the waiting time shorter.

3. In some categories the audit standards were not met as the doctors did not request the investigations timely. Therefore we recommend emphasizing the importance of regular investigations and screening of the patients to the doctors who conduct the clinic.

4. We also recommend counseling the patients regarding regular follow up as certain percentage of non adherence to audit standards was due to patients' lack of interest.

\section{Re-audit}

A re-audit is planned one year after implementing the recommendations.

\section{References}

1. Management of diabetes mellitus, guidelines, Ministry of Health Care and Nutrition.

2 Management of diabetes mellitus in adults, American Diabetes Association, 1994: p86-91.

3. AACE Diabetes mellitus guidelines, Endocr Pract. 2007 ; 13(Suppl 1): 2007.

4. Sacks DB, Bruns DE. Guidelines and recommendations for Laboratory Analysis in the Diagnosis and Management of Diabetes Mellitus. Clinical Chemistry 2002; 48: 436-72.

5. Brown JB, Harris SB. The role of patient, physicians and systemic factors in the management of type 2 diabetes mellitus. Family Practice 19(4): 344-9.

6. Schmittdiel JA. Uratsu CS. The effectiveness of diabetes care management in managed care. Am J Manage Care 2009 May; 15(5): 295-301.

7. Diabetes control in primary care setting: A retrospective study in 651 patients. Al-Hussein FA, Ann Saudi Med 2008 July-Aug; 28(4) 267-71.

8. Sheikh K. Bullock CM, Jiang Y, Ketner SD. Adherence to guidelines for and disparities in diabetes care utilization in Medicaid children. J Pediatr Endocrinol Metab 2008 April; 21(4): 349-58. 